\title{
Tripartite of Malnutrition: Co-existence of Underweight, Overweight and Micronutrient Deficiency Among Children in Kisumu County, Kenya
}

\author{
Caroline J. Sawe ( $\nabla$ csawe@cartafrica.org ) \\ University of Nairobi \\ W Kogi-Makau \\ University of Nairobi \\ Grace A. K. Ettyang \\ Moi University \\ Kimamo CO \\ University of Nairobi
}

\section{Research Article}

Keywords: Tripartite, malnutrition, underweight, overweight, micronutrient, deficiency

Posted Date: February 19th, 2021

DOI: https://doi.org/10.21203/rs.3.rs-209539/v1

License: (c) (i) This work is licensed under a Creative Commons Attribution 4.0 International License.

Read Full License 


\title{
Tripartite of malnutrition: Co-existence of underweight, overweight and micronutrient deficiency among children in Kisumu County, Kenya
}

\author{
Caroline J. Sawe ${ }^{1}$, W Kogi-Makau ${ }^{1}$, Grace A. K. Ettyang ${ }^{2}$, CO Kimamo ${ }^{3}$ \\ Corresponding author: Caroline J. Sawe, Department of Food Science, Nutrition and Technology, University of \\ Nairobi; Tel: +254 721540248 Email: csawe@ cartafrica.org
}

\begin{abstract}
Background: Challenges facing Kenyan government include childhood underweight, overweight and micronutrient deficiencies. These forms of malnutrition have existed in several regions of the world with their consequences spreading to old age. A total of $11 \%$ of Kenyan children are underweight while $4 \%$ are overweight. Micronutrient deficiency affects 2 billion people worldwide with iron and Vitamin A Deficiency affecting $60 \%$ and $70 \%$ of children in Sub Saharan Africa respectively. Only $72 \%$ of Kenyan children consume diets rich in Vitamin A. This study assessed the status of underweight, overweight and micronutrient deficiency among children in Kisumu County, Kenya.

Methods: Cross sectional study was used that recruited 384 children aged less than 2 years. Anthropometric measurements assessed nutritional status while food frequency questionnaire assessed nutrient intake of children. STATA V.14 analyzed data. Bivariate analysis linked outcome and independent variables while multinomial logistic regression assessed factors influencing malnutritional status of children.

Results: A total of $23 \%$ of children were underweight while $30 \%$ were overweight. Only $10 \%$ consumed carbohydrate adequate diets while $31 \%$ consumed foods rich in iron. Mothers earning more than Ksh 3,000 had 60\% higher risks of their children being underweight compared to those earning less than Ksh 2,999 per month while children living in permanent houses had 50\% lower risks of being underweight compared to those living in temporary houses. Children aged between 19 and 24 months had $80 \%$ higher risks of being overweight compared to those aged below 6 months while those living in permanent houses had $40 \%$ lower risks of being overweight compared
\end{abstract}


to those living in temporary houses. Those with inadequate carbohydrate and iron intake had $20 \%$ and $80 \%$ lower risks respectively of being overweight compared to those with adequate intake.

Conclusion: In Kisumu county, $23 \%$ of children were underweight while $30 \%$ were overweight. Only 31\% consumed diets rich in iron sources. Mothers' income, type of housing and micronutrient intake were associated with nutritional status of children. Interventions and policies to target this early age as is window period of opportunity.

key words: Tripartite, malnutrition, underweight, overweight, micronutrient, deficiency

\section{Introduction}

Childhood underweight, overweight and micronutrient deficiencies are common challenges facing Kenya's health sector. The combination of these forms of malnutrition reflects the three sides of one predicament in a similar population $(1,2)$. Underweight is an indicator of both wasting and stunting while overnutrition includes overweight, obesity and non-communicable diseases while micronutrient deficiencies consists of inadequacies of vitamins and minerals in human bodies (3). Research evidence is now challenging global reports indicating that cases of childhood underweight are higher and overweight cases being lower in developing countries compared to developed countries (2). Undernutrition has been reported to the major cause of death among children with $18 \%$ of them approximated to be underweight (4).

Globally, the number of overweight children rose from 30 million in 2010 to 38 million in 2019. A total of 10 million are from Africa with 13\% residing in Southern Africa and 4\% from Eastern Africa (5). Compared to industrialized countries, developing countries are struggling with its rise and presently, it is a worrying phenomenon (6-8). It is a public health concern that is no longer associated with societal prestige as before (9). Childhood overweight can be due several factors that are not limited to poor feeding and breastfeeding practices, and low physical activity. If not well managed at an early age, it can predispose individuals to non-communicable diseases including diabetes mellitus, cardio vascular diseases, adulthood obesity and can lead to premature deaths $(10,11)$. 
Micronutrient deficiency is a silent condition that has affected over 2 billion people in the world. It is rampant in developing countries with consequences affecting health, growth and development. It is at times referred to as hidden hunger of malnutrition. Compared to macronutrients (carbohydrates, proteins and fats) that are needed in large amounts, micronutrients are mineral and vitamins that are needed in our bodies in small quantities. Globally, the common micronutrient deficiencies among children are iron, Vitamin A, folate, zinc and Vitamin $B_{12}(12)$. It is estimated that over $60 \%$ and $70 \%$ of children from Sub Saharan Africa suffer from Iron and Vitamin A Deficiencies (VAD) respectively and Kenya has the highest prevalence of VAD at $85 \%$ (13). Coupled with rapid growth and development, sources of nutrient deficiency among children in disadvantaged settings include; poverty, poor health care services, illness; and poor feeding and cultural practices. It is also evident that their negative effects extend to adulthood and are; night blindness, anemia, poor cognitive development, poor school performance and reduced economic security (14).

These three forms of malnutrition have existed in several regions of the world with their consequences spreading to old age and have undesirable impacts to the economy of any government $(15,16)$. It has been reported that major health challenges facing Kenyan government are childhood underweight, overweight and micronutrient deficiencies. The 2014 KDHS reported that $11 \%$ and $4 \%$ of Kenyan children are underweight and overweight respectively and only $72 \%$ consumed foods rich in Vitamin A and out of which 65\% resided in rural parts of the country. It also revealed that only $33 \%$ of children consumed iron-rich foods with $13 \%$ of them residing in rural areas compared to $7 \%$ from urban regions $(17,18)$. This study therefore aimed at assessing the underweight, overweight and micronutrient status of children aged less than two years in Kisumu County, Kenya

\section{Methods}

\section{Study design and participants}

This was a cross sectional study that employed quantitative study design. It recruited 384 children aged less than 2 years from Nyakach Sub county of Kisumu County, Kenya.

\section{Eligibility criteria}


All children aged less than two years residing in Nyakach Subcounty were eligible into the study but excluded those who had chronic diseases like cancer, TB, malaria and those who were on prescribed drugs during the time of data collection. This was because these conditions and medications have an adverse effect on the nutritional status of children and affected the dietary intake of food. Those who refused to consent were also excluded from the study.

\section{Sampling procedures}

A total of 384 children aged below two years were recruited from Nyakach sub county in Kisumu County. Taking each group as a stratum, an estimated 40,000 children aged less than two years reside in the sub county in the proportion of 2: 3: 3: 2 for ages less than 6 months, 6 to 12 months, 12 to 18 months and 18 to 24 months respectively. Therefore 78 children from each stratum for ages below six months and those between 18 and 24 months were recruited while for those aged 6 to 12 months and 13 to 18 months, each recruited 114 children. From each age strata, children were randomly selected until the desired sample size was achieved. This was to ensure that each child in the study area had an equal chance of being recruited.

\section{Anthropometric measurements and nutritional status}

Questionnaires on child socio demographic characteristics were administered to the mother's while child's date of birth and weight were recorded on anthropometric form. The SECA and salter weighing scales were used to take the weights of the children in kilograms. Before a child was weighed, the Research Assistant (RA) ensured that the scale reading was at zero mark. For irritable children or those who feared to be weighed alone, their weights were gotten by subtracting their mother's weight alone with that of them with their mothers. Children were weighed with minimal clothing. Exact ages of children were confirmed from the health cards. To ensure accuracy, the measurements were taken thrice, and the mean computed. Recording of weight were done to the nearest $0.1 \mathrm{~kg}$. Each child's measurements and weights were recorded in a unique identifier number that was then merged with the socio demographic and nutrient intake data. The underweight and overweight indice was computed using Weight-for-Age WHO Z score (WAZ) classification. Children whose $Z$ scores were $\leq-2$ were classified as underweight, between $>-2 \mathrm{SD}$ and $\leq 2 \mathrm{SD}$ were classified as normal and those $>2$ SD were classified as overweight (19). 


\section{Nutrient intake}

Nutrient intake was assessed using the Food frequency questionnaire (FFQ). FFQ approximated the typical dietary intake of an children over a period of up to 1 month $(20,21)$. In this study, it was administered to mothers of children to determine the average daily food intake based on local consumed foods in the region. The mothers were probed, and model pictures of local foods were used to ask if children had consumed certain foods in the past one month and if so, in what estimated amount per each meal. The FFQ had a total of 26 locally consumed foods. For this study, the nutrients that were of interest were carbohydrates, proteins, fats, iron and Vitamin A. Mother gave this information on behalf of their children.

\section{Covariates}

The study assessed socio demographic characteristics of children and they included; child's sex, age in months, duration of exclusive breastfeeding in months (less than 3, 5 to 5, 6, more than 6 and still breastfeeding), when stopped breastfeeding in months (less than $6 ; 6$ to $12 ; 13$ to 18,19 to 24 and still breastfeeding), mother's marital status (single or widowed or divorces; and married), mother's highest education attained (primary, secondary and tertiary), mother's and father's monthly income in Kenyan shillings ( (less than 2,999 or more than 3,000), type of house family lived in (semi-permanent or permanent), size of housing in terms of rooms ( single, double, 3 or more), and amount of house rent paid in Kenyan Shillings (none, less than 3,000; and more than 3,001). For nutritional status (overweight, normal and overweight) and for nutrient intake, the key nutrients were carbohydrate, protein, fat, iron and vitamin (Adequate or inadequate)

\section{Ethical considerations}

Ethical approval and clearance were sought from Moi University Institutional Research and Ethical Committee (IREC) approval No. 0001567. Confidentiality of the participants was ensured by using anonymous numbers. After explaining the purpose of the study, the mothers who accepted their children to participate in the study consented on behalf of their children voluntarily and were allowed to withdraw from the study any time without intimidation. All research assistants had to do an online Protection of Human Subjects tests and passed before collecting data (22). Confidentiality of data collected from participants were ensured by sealing them in envelopes, transported and kept under lock and key in the Researcher's office. Data entered in the computer 
were protected using password. All ethical procedures were followed according to the IREC regulations and guidelines

\section{Statistical analysis}

ENA for SMART software computed the exact ages of children after date of survey and date of birth of children were entered. It also computed the underweight and overweight indice based on WHO Z scores from the sex, weight and age variables of the children. The computed information was then exported to STATA V.14 for analysis after merging with socio demographic characteristics and dietary intake data. Characteristics of children were described using univariate analysis while bivariate statistics analyzed the association between child overweight and overweight status with the independent variables and the nutrient intake. All the factors in the bivariate analysis that had $\mathrm{p} \leq 0.05$ were considered for multinomial logistic regression to assesses the factors that influenced status of malnutrition and dietary intake among children in Kisumu County (23). 


\section{Results}

Table 1 summarized the characteristics of 384 children who participated in the study. A total of $51 \%$ were boys and $20 \%$ children were aged below 6 months. Of all the children, only $47 \%$ were exclusively breastfed for the first 6 months of life though $11 \%$ were still breastfeeding while $17 \%$ stopped breastfeeding at the age between 6 and 12 months. A total of $68 \%$ of the mothers were married and $40 \%$ had schooled up to secondary only. Only $42 \%$ of children reported to be living in two roomed houses while 55\% lived in semi-permanent houses.

Table 1 Socio Demographic Characteristics of children

\begin{tabular}{|c|c|c|c|c|c|}
\hline Characteristic & $n=384$ & $\%$ & Characteristic & $n=384$ & $\%$ \\
\hline Child's age group in months & & & Mother's monthly income (ksh) & & \\
\hline$<6$ & 78 & 20.31 & $<2,999$ & 212 & 55.21 \\
\hline 6 to 12 & 114 & 29.69 & $>3,000$ & 172 & 44.79 \\
\hline 13 to 18 & 114 & 29.69 & Mother's level of education & & \\
\hline 19 to 24 & 78 & 20.31 & $\leq$ Primary & 138 & 35.94 \\
\hline Sex & & & Secondary & 152 & 39.58 \\
\hline Female & 194 & 50.51 & Tertiary & 94 & 24.48 \\
\hline Male & 190 & 49.48 & Father's level of income (Ksh) & & \\
\hline Duration of exclusive BF in months & & & $<2,999$ & 238 & 61.98 \\
\hline$<3$ & 24 & 6.25 & $>3,000$ & 146 & 38.02 \\
\hline 4 to 5 & 124 & 32.29 & Type of housing & & \\
\hline 6 & 182 & 47.40 & Semi-permanent & 210 & 54.69 \\
\hline$>6$ & 12 & 3.13 & Permanent & 174 & 45.31 \\
\hline Still BF & 42 & 10.94 & Monthly Rent amount (Ksh) & & \\
\hline When child stopped BF in months & & & None & 126 & 32.81 \\
\hline$<6$ & 82 & 6.25 & $<3000$ & 174 & 45.31 \\
\hline 6 to 12 & 66 & 17.19 & $>3001$ & 84 & 21.88 \\
\hline 13 to 18 & 42 & 10.94 & Size of housing & & \\
\hline 19 to 24 & 14 & 3.65 & Single & 132 & 34.38 \\
\hline Still BF & 180 & 46.68 & Double & 160 & 41.67 \\
\hline Mother's marital status & & & $\geq 3$ rooms & 92 & 23.96 \\
\hline Single/ divorce/widow & 122 & 31.77 & & & \\
\hline Married & 262 & 68.23 & & & \\
\hline
\end{tabular}

Figure 1 revealed that a total of $23 \%$ and $30 \%$ of the children were underweight and overweight respectively with $31 \%$ of children aged less than 6 being underweight while $32 \%$ of those aged 
between 6 and 12 months being overweight. It also revealed that as children grew, their weight compared to their age increased.

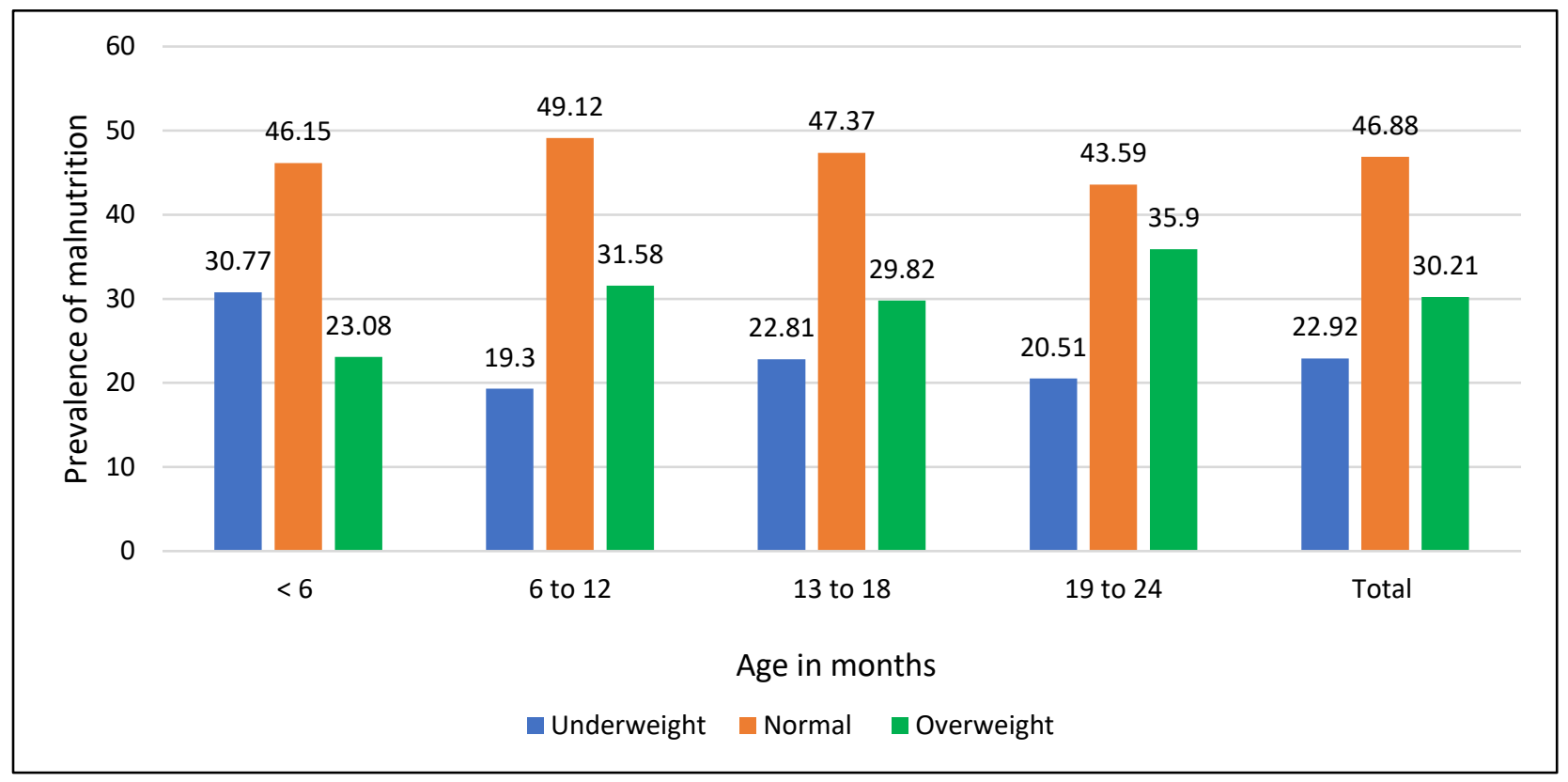

Figure 1 Prevalence of undernutrition and overnutrition among children in Kisumu County

Figure 2 revealed only $31 \%$ and $84 \%$ of children consumed diets that were rich in iron and vitamin A sources respectively while $90 \%$ consumed diet that was adequate in carbohydrate sources.

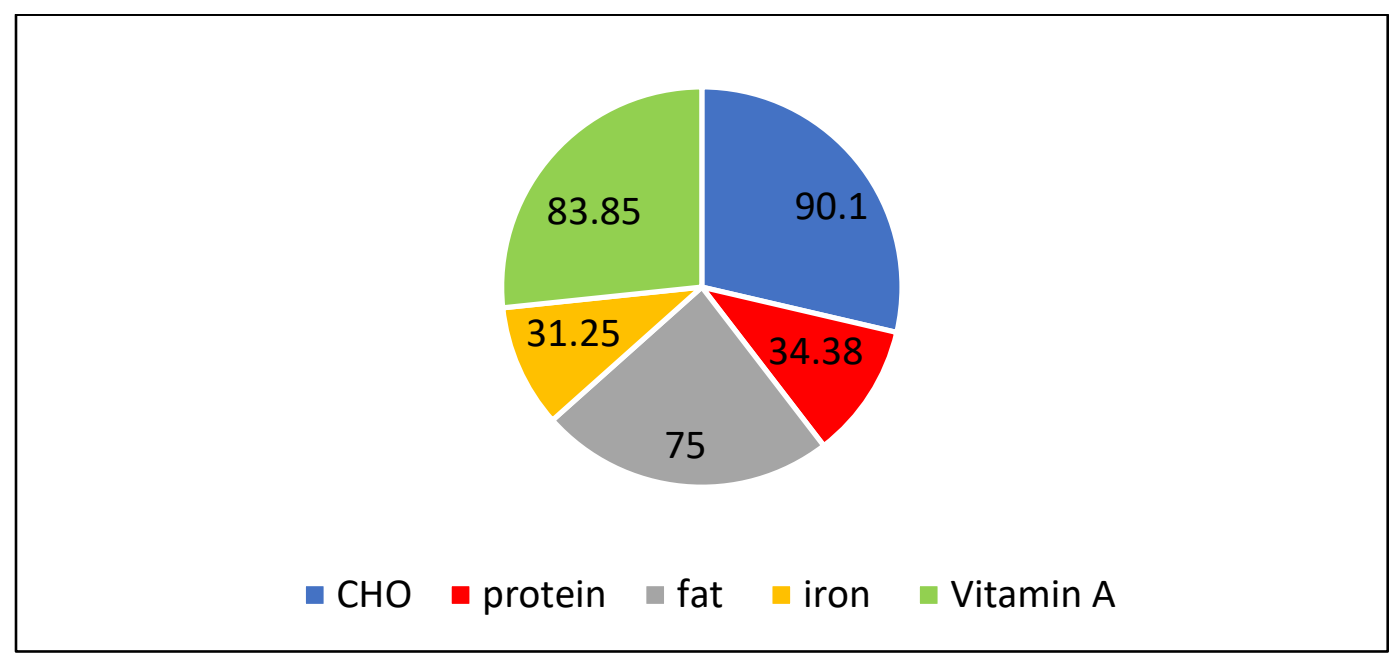

Figure 2 Adequacy of nutrient intake among children in Kisumu County 
Table 2 showed the factors that were linked to underweight and overweight status among children aged less than 2 years in Kisumu county. These factors were; child's duration of exclusive breastfeeding ( $\mathrm{p} \leq 0.001)$, time child stopped breastfeeding ( $\mathrm{p}=0.002)$, mother's marital status ( $\mathrm{p}=0.005)$, mother's monthly income $(\mathrm{p} \leq 0.001)$, amount of rent family pays for housing $(\mathrm{p}=0.026)$, size of housing $(\mathrm{p}=0.007)$, intake of fat $(\mathrm{p} \leq 0.001)$ and intake of iron $(\mathrm{p}=0.029)$. 
Table 2 Bivariate analysis on relationship between child stunting and other variables

\begin{tabular}{|c|c|c|c|c|c|c|c|c|}
\hline \multirow[t]{2}{*}{ Characteristic } & \multirow[b]{2}{*}{$\%$} & \multicolumn{2}{|c|}{ Nutritional status in $\%(n=384)$} & \multicolumn{5}{|c|}{ Adequacy of Dietary intake in $\%(n=384)$} \\
\hline & & Underweight & Overweight & $\mathrm{CHO}$ & Protein & Fat & Iron & Vit A \\
\hline \multicolumn{9}{|c|}{ Child's age group in months } \\
\hline Less than 6 & 20.31 & 30.77 & 23.08 & 94.87 & 33.33 & 71.93 & 31.58 & 85.96 \\
\hline 6 to 12 & 29.69 & 19.30 & 31.58 & 87.72 & 20.51 & 64.10 & 12.82 & 79.49 \\
\hline 13 to 18 & 29.69 & 22.81 & 29.82 & 92.98 & 33.33 & 78.95 & 31.58 & 78.95 \\
\hline 19 to 24 & 20.31 & 20.51 & 35.90 & 84.62 & 51.28 & 84.62 & 48.72 & 92.31 \\
\hline$P$ value & & 0.483 & & 0.093 & 0.001 & 0.016 & $<0.001$ & 0.055 \\
\hline \multicolumn{9}{|c|}{ Duration of Exclusive Breastfeeding in months; for } \\
\hline Less than 3 & 6.25 & 16.67 & 50.00 & 100.00 & 33.33 & 100.00 & 33.33 & 83.33 \\
\hline 4 to 5 & 32.29 & 20.97 & 30.65 & 90.32 & 14.52 & 74.19 & 12.90 & 74.19 \\
\hline 6 & 47.40 & 23.08 & 29.67 & 87.91 & 30.77 & 69.23 & 28.57 & 86.81 \\
\hline More than 6 & 3.13 & 0.00 & 83.33 & 66.67 & 66.67 & 33.33 & 16.67 & 83.33 \\
\hline Still BF & 10.94 & 38.10 & 4.76 & 100.00 & 100.00 & 100.00 & 100.00 & 100.00 \\
\hline$P$ value & & $<0.001$ & & 0.004 & $<0.001$ & $<0.001$ & $<0.001$ & 0.001 \\
\hline \multicolumn{9}{|c|}{ When child stopped BF in months } \\
\hline$<6$ & 6.25 & 26.83 & 31.71 & 95.12 & 4.88 & 95.12 & 4.88 & 85.37 \\
\hline 6 to 12 & 17.19 & 36.36 & 33.33 & 93.94 & 9.09 & 87.88 & 6.06 & 81.82 \\
\hline 13 to 18 & 10.94 & 23.81 & 28.57 & 71.43 & 14.29 & 61.90 & 9.52 & 66.67 \\
\hline 19 to 24 & 3.65 & 0.00 & 42.86 & 85.71 & 14.29 & 42.86 & 0.00 & 57.14 \\
\hline Still BF & 46.88 & 17.78 & 27.78 & 91.11 & 63.333 & 66.67 & 60.00 & 90.00 \\
\hline$P$ value & & 0.013 & & $<0.001$ & $<0.001$ & $<0.001$ & $<0.001$ & $<0.001$ \\
\hline \multicolumn{9}{|l|}{ Mother's marital status } \\
\hline Married & 68.23 & 24.59 & 27.87 & 93.44 & 29.51 & 86.89 & 26.23 & 81.97 \\
\hline Single/divorce/widow & 31.77 & 22.14 & 31.30 & 88.55 & 36.64 & 69.47 & 33.59 & 84.73 \\
\hline$P$ value & & 0.756 & & 0.135 & 0.171 & $<0.001$ & 0.148 & 0.493 \\
\hline \multicolumn{9}{|c|}{ Mother's monthly income in Ksh } \\
\hline$<2,999$ & 55.21 & 11.32 & 31.13 & 86.79 & 47.17 & 66.04 & 43.40 & 82.08 \\
\hline$>3,000$ & 44.79 & 37.21 & 29.07 & 94.19 & 18.60 & 86.05 & 16.28 & 86.05 \\
\hline
\end{tabular}




\begin{tabular}{|c|c|c|c|c|c|c|c|c|}
\hline \multirow{2}{*}{\multicolumn{2}{|c|}{ P value }} & \multicolumn{2}{|l|}{$<0.001$} & \multirow[t]{2}{*}{0.016} & \multirow[t]{2}{*}{$<0.001$} & \multirow[t]{2}{*}{$<0.001$} & \multirow[t]{2}{*}{$<0.001$} & \multirow[t]{2}{*}{0.293} \\
\hline & & & & & & & & \\
\hline$<2,999$ & 61.98 & 18.49 & 31.09 & 91.60 & 32.77 & 72.27 & 27.73 & 83.19 \\
\hline$>3,000$ & 38.02 & 30.14 & 28.77 & 87.67 & 36.99 & 79.45 & 36.99 & 84.93 \\
\hline$P$ value & & 0.027 & & 0.211 & 0.399 & 0.115 & 0.058 & 0.653 \\
\hline \multicolumn{9}{|c|}{ Type of housing } \\
\hline Temporary & 54.69 & 25.71 & 33.33 & 96.19 & 26.67 & 87.62 & 87.62 & 84.76 \\
\hline Permanent & 45.32 & 19.54 & 26.44 & 82.76 & 43.68 & 59.77 & 59.77 & 82.76 \\
\hline$P$ value & & 0.038 & & $<0.001$ & $<0.001$ & $<0.001$ & 0.010 & 0.595 \\
\hline \multicolumn{9}{|c|}{ Amount of rent paid in Ksh } \\
\hline None & 32.81 & 25.40 & 25.40 & 90.48 & 26.98 & 88.89 & 25.40 & 73.02 \\
\hline$<3000$ & 45.31 & 21.84 & 31.03 & 88.51 & 43.68 & 65.52 & 40.23 & 88.51 \\
\hline$>3001$ & 21.88 & 21.43 & 35.71 & 92.86 & 26.19 & 73.81 & 21.43 & 90.48 \\
\hline$P$ value & & 0.593 & & 0.540 & 0.002 & $<0.001$ & 0.002 & $<0.001$ \\
\hline \multicolumn{9}{|c|}{ Size of house family lives } \\
\hline Single & 34.38 & 21.21 & 31.82 & 90.91 & 43.94 & 72.73 & 40.91 & 80.30 \\
\hline Double & 41.67 & 21.35 & 26.25 & 91.25 & 36.25 & 75.00 & 32.50 & 87.50 \\
\hline$\geq 3$ rooms & 23.96 & 28.26 & 34.78 & 86.96 & 17.39 & 78.26 & 15.22 & 82.61 \\
\hline$P$ value & & 0.192 & & 0.508 & 0.000 & 0.642 & $<0.001$ & 0.234 \\
\hline \multicolumn{9}{|c|}{ Carbohydrate intake } \\
\hline Adequate & 90.10 & 24.86 & 31.21 & 100.00 & 38.15 & 80.35 & 34.68 & 87.86 \\
\hline Inadequate & 9.90 & 5.26 & 21.05 & 0.00 & 0.00 & 26.32 & 0.00 & 47.37 \\
\hline$P$ value & & 0.001 & & $<0.001$ & $<0.001$ & $<0.001$ & $<0.001$ & $<0.001$ \\
\hline \multicolumn{9}{|c|}{ Protein intake } \\
\hline Adequate & 34.38 & 22.73 & 24.24 & 100.00 & 100.00 & 77.27 & 89.39 & 100.00 \\
\hline Inadequate & 65.63 & 23.02 & 33.33 & 84.92 & 0.00 & 73.81 & 0.79 & 75.00 \\
\hline$P$ value & & 0.135 & & $<0.001$ & $<0.001$ & 0.457 & $<0.001$ & $<0.001$ \\
\hline \multicolumn{9}{|l|}{ Fat intake } \\
\hline Adequate & 75 & 28.47 & 26.39 & 96.53 & 35.42 & 100.00 & 33.33 & 86.11 \\
\hline Inadequate & 25 & 6.25 & 41.67 & 70.83 & 31.25 & 0.00 & 25.00 & 77.08 \\
\hline P value & & $<0.001$ & & $<0.001$ & 0.547 & $<0.001$ & 0.127 & 0.037 \\
\hline
\end{tabular}


Further analysis on Table 3 shows the factors associated with malnutrition from bivariate analysis revealed that children whose mothers earned more than Ksh 3,000 per months had 60\% (95\% CI 2.796 to 12.373 ) higher relative risks of being underweight compared to those whose mothers were earning less than Ksh 2,999 per month while families who lived in permanent houses had 50\% (95\% CI 0.246 to 1.018) lower risks of their children being underweight compared to those who lived in temporary houses. It also found that the relative risks of children being overweight was $80 \%$ (95\% CI 0.814 to 82.94) higher for those aged between 19 to 24 months compared to those aged less than 6 months; $40 \%$ (95\% CI 0.217 to 0.833 ) lower for those living in permanent houses compared to those living in temporary houses; $20 \%$ (95\% CI 0.057 to 0.56 ) lower for those with inadequate carbohydrate intake compared to those with adequate intake; and 20\% (95\% CI 1.21 to 5.405) more for those with inadequate iron intake compared to those with adequate intake. 
Table 3 Regression analysis

\begin{tabular}{|c|c|c|c|}
\hline $\begin{array}{l}\text { Status of malnutrition /Characteris } \\
\text { Underweight }\end{array}$ & & RRR & $\mathrm{p}$ value \\
\hline When child was stopped & $<6$ & 1 & \\
\hline breastfeeding in months & 6 to 12 & $0.8262(0.180$ to 3.795$)$ & 0.806 \\
\hline & 13 to 18 & $1.2431(0.275$ to 5.627$)$ & 0.778 \\
\hline & 19 to 24 & $2.3006(0.000$ to 0.000$)$ & 0.995 \\
\hline & Still BF & $4.1843(0.728$ to 24.061$)$ & 0.109 \\
\hline Mother's monthly income (Ksh) & $<2,999$ & 1 & \\
\hline & $>3,000$ & $5.882(2.796$ to 12.373$)$ & $<0.001$ \\
\hline Type of house family lives & Temporary & 1 & \\
\hline & Permanent & $0.500(0.246$ to 1.018$)$ & 0.056 \\
\hline Monthly house rent (Ksh) & None & 1 & \\
\hline & $<3000$ & $1.815(0.843$ to 3.909$)$ & 0.128 \\
\hline & $>3001$ & $0.935(0.391$ to 2.237$)$ & 0.879 \\
\hline Carbohydrate intake & Adequate & 1 & \\
\hline & Inadequate & $0.182(0.031$ to 1.080$)$ & 0.061 \\
\hline Fat Intake & Adequate & 1 & \\
\hline & Inadequate & $0.532(0.270$ to 1.633$)$ & 0.270 \\
\hline Normal & & & \\
\hline Overweight & & & \\
\hline When child & $<6$ & 1 & \\
\hline breastfeeding in months & 6 to 12 & $0.250(0.077$ to 0.815$)$ & 0.022 \\
\hline & 13 to 18 & $0.262(0.084$ to 0.819$)$ & 0.021 \\
\hline & 19 to 24 & $8.217(0.814$ to 82.940$)$ & 0.074 \\
\hline & Still BF & $0.106(0.016$ to 0.691$)$ & 0.019 \\
\hline Mother's monthly income (Ksh) & $<2,999$ & 1 & \\
\hline & $>3,000$ & $1.412(0.726$ to 2.748$)$ & 0.310 \\
\hline Type of house family lives & Temporary & 1 & \\
\hline & Permanent & $0.425(0.217$ to 0.833$)$ & 0.013 \\
\hline Monthly house rent (Ksh) & None & 1 & \\
\hline & $<3000$ & $1.345(0.395$ to 2.660$)$ & 0.395 \\
\hline & $>3001$ & $1.311(0.612$ to 2.811$)$ & 0.486 \\
\hline Carbohydrate intake & Adequate & 1 & \\
\hline & Inadequate & $0.179(0.057$ to 0.560$)$ & 0.003 \\
\hline Fat intake & Adequate & 1 & \\
\hline & Inadequate & $2.558(1.210$ to 5.405$)$ & 0.014 \\
\hline
\end{tabular}

RRR = Relative Risk Ratio

Ksh = Kenyan Shillings (I USD==Ksh 100)

$\mathrm{p}=0.05$ 


\section{Discussion}

This study found that a total of $23 \%$ and $30 \%$ of children in Kisumu were underweight and overweight respectively. These results were higher compared to the national prevalence from the KDHS 2014 report that reported 11\% for underweight and 4\% for overweight among children in Kenya. The same survey report revealed that $7 \%$ and $4 \%$ of children in Kisumu county were underweight and overweight respectively, results that highly varied with those of this study (17). The higher prevalence in overweight among children in this study could be attributed to children feeding on high calorie diets and being involved in less activities with long periods on the screens and electronics. This predisposes them to weight gain at an early age. High poverty levels and house hold food insecurity situations in Kisumu County could still have contributed to the higher prevalence in underweight status among children (24). It was further revealed that children aged less than 6 months recorded the highest prevalence of underweight at $31 \%$ compared to children in other age groups. Breastmilk is the gold standard for infant feeding because of its unmatched benefits. It has a perfect mix of all key nutrients essential for growth and development, is easily digested, has adequate antibodies that protect the infant against diseases, infections and episodes of diarrhea thus reducing chances of hospitalizations (25). UNICEF recommends that all children be exclusively breastfed for the first six months of life but only $61 \%$ of Kenyan children were exclusively breastfed with $63 \%$ being from Kisumu county while in this study only $47 \%$ of children were exclusively breastfed for six months and $32 \%$ were introduced to complementary feeds when they were aged between 4 and 5 months. It was also found that $6 \%$ of children in this study were exclusively breastfed for the first 3 months of life. According to KDHS 2014, 58\% were introduced to complementary at an early age of 4 to 5 months (26-29). Early cessation of exclusive breastfeeding in poor settings like in Kisumu County has been promoted by the high prevalence of HIV; and demographic factors like parental education and socio cultural practices and high poverty levels (30). Mixed feeding at an early age is usually discouraged because it exposes children to malnutrition and that more often, the complementary feeds introduced are usually of low quality nutritionally, insufficient in form of quality and the amount in relation to child's needs; and the environment for preparation might not even be fit hygienically (31). At early age also, most infants have started exploring the environment around them and may be exposed to other contaminants like soil and dirty toys that further predisposes them to other diseases leading to malnutrition (32). In this study, mothers' monthly income was found to be related to child's 
underweight status. In most household's mothers' income is spread to cater for most household expenses with little left to cater for the nutritional needs of the family members including those of young children. This study agreed with other surveys that were done in Guinea (33) and in Nigeria (34).

A trend in overweight status according to age groups revealed that as children grew, the rate of overweight increased. Culturally, communities have perceived overweight and obese children as those that are healthy and are being taken care off well by their parents. With this in mind, parents tend to feed them with lots of unhealthy foods as they grow so that they can fulfil the community expectations and this diet if combined with less activity levels, children tend to be overweight and become vulnerable to non-communicable disease later in life (35). Young overweight children at times are overfed since their parents think that food is never enough for them while in some communities, grandparents view them as a sign of their success and they recover easily from illnesses $(35,36)$. It was found that the time when child stopped breastfeeding, type house family lived; and intake of carbohydrate and fat were associated with child overweight status. The importance of breastmilk among children is well documented with evidence showing that breastmilk has a protective effect on childhood overweight (37). Children who were never or breastfeed for a shorter duration were likely to be overweight and obese compared to those who were exclusively breastfed and continued with breastmilk until they were two years and beyond (38). Children living in permanent houses had higher risks of being overweight because of better living conditions and this concurs with a study that was done in Turkey (39). Children from such homes engage in less physical activities, and watch more TV screens and can easily access to diets that have lots of fats and carbohydrates. These nutrients predispose individuals to overweight even at an early age

This study showed that even though $90 \%$ of children consumed diets that were adequate in Carbohydrate, only $31 \%$ and $34 \%$ consumed foods that were rich in iron and protein sources. In the recent past, African countries have increasingly substituted their diets with westernized diets that are usually characterized by micronutrient deficiencies and low in nutrients (40) and abandoned their own their own indigenous foods that were beneficial to health and enhanced household food security because of their nutrient density and dietary diversity characteristics (41, 42). Continued consumption of low-dense foods has increased the risk of malnutrition as shown in this study. Because of the high poverty levels and many family members in counties like Kisumu 
county, most households will tend consume foods that are high in carbohydrate content because they are easily available and affordable; and these patterns of consumption will tend to deny family members key nutrients like iron that are beneficial to health. Animal foods that majorly provide micronutrients like iron mostly expensive and not readily available in most of these poor settings (43).

\section{Conclusions}

The three forms of malnutrition are public health issues that need Kenyan government attention. The study revealed a high prevalence of childhood underweight at $23 \%$ and overweight at $30 \%$. Only $31 \%$ consumed diets rich in iron sources. Mothers' monthly income, houses where children lived and micronutrient intake were linked to nutritional status of children. Nutrition-sensitive interventions and policies that target children aged less than two years need to be formulated and implemented for timely prevention of these burden of malnutrition among children in Kenya. Further research is recommended to investigate the factors associated with the triple burden of malnutrition among children in developing countries.

\section{Acknowledgement}

The authors would like the acknowledge the support of all the study participants, as well as the mothers of the children and University of Nairobi where the CS was studying.

\section{Author Information}

${ }^{1}$ Department of Food Science, Nutrition and Technology, College of Agriculture and Visionary Sciences, University of Nairobi

2 Department of Human Nutrition, College of Health Sciences, Moi University

${ }^{3}$ Department of Psychology, College of Humanities and Social Sciences, University of Nairobi.

\section{AUTHOR CONTRIBUTION}

C. J. S was the main researcher and student who conceptualized and collected data. She did data analysis and interpretation, drafted and finalized this manuscript. W. K. M was the main student supervisor and provided the guidance from conceptualization of the research objectives, 
methodology, data collection, analysis, and interpretation of the results. G.A.K.E was student supervisor and provided the guidance from conceptualization of the research objectives, methodology, data collection, analysis, and interpretation of the results. and C.O.K was student supervisor and provided the guidance from conceptualization of the research objectives, methodology, data collection, analysis, and interpretation of the results

All supervisors were very key in development, drafting and finalizing of this manuscript.

\section{FUNDING}

"This research was supported by the Consortium for Advanced Research Training in Africa (CARTA). CARTA is jointly led by the African Population and Health Research Center and the University of the Witwatersrand and funded by the Carnegie Corporation of New York (Grant No-B 8606.R02), Sida (Grant No:54100113), the DELTAS Africa Initiative (Grant No: 107768/Z/15/Z) and Deutscher Akademischer Austauschdienst (DAAD). The DELTAS Africa Initiative is an independent funding scheme of the African Academy of Sciences (AAS)'s Alliance for Accelerating Excellence in Science in Africa (AESA) and supported by the New Partnership for Africa's Development Planning and Coordinating Agency (NEPAD Agency) with funding from the Wellcome Trust (UK) and the UK government. The statements made and views expressed are solely the responsibility of the Fellow".

\section{Availability of data and materials}

Data is not publicly available as per the ethical forms. It can only be available on special request from Caroline Sawe (carolsawej@yahoo.com)

\section{Ethics approval and consent to participate}

Ethical approval and clearance were sought from Moi University Institutional Research and Ethical Committee (IREC) approval No. 0001567. Approval was also sought from the sub county demonstration to conduct the research. Confidentiality of the participants was ensured by using anonymous numbers and informed consent was gotten voluntarily from the mothers on behalf of their children. Completed collected data from the field were sealed in envelopes, transported and kept under lock and key in the Researcher's office. Data entered in the computer were protected 
using password. All ethical procedures were followed according to the IREC regulations and guidelines

\section{Consent for publication}

Not applicable

\section{Competing interests}

All the authors declare that they have no competing interest

\section{REFERENCES}

1. Elizabeth K. Nutrition and Malnutrition. The Encyclopedia of Child and Adolescent Development. 2019:1-18.

2. Micha R, Mannar V, Afshin A, Allemandi L, Baker P, Battersby J, et al. 2020 Global nutrition report: action on equity to end malnutrition. 2020.

3. Nutrition, Improving Child. The achievable imperative for global progress. New York, NY: UNICEF. 2013.

4. De Onis M, Blössner M, Borghi E, Frongillo E, Morris R. WHO global database on child growth and malnutrition. Geneva: WHO. 2003.

5. World Health Organization. UNICEF/WHO/The World Bank Group joint child malnutrition estimates: levels and trends in child malnutrition: key findings of the 2020 edition. 2020.

6. Lachat C, Otchere S, Roberfroid D, Abdulai A, Seret FMA, Milesevic J, et al. Diet and physical activity for the prevention of noncommunicable diseases in low-and middle-income countries: a systematic policy review. PLoS medicine. 2013;10(6):e1001465.

7. Wojcicki JM, Heyman MB. Malnutrition and the Role of the Soft Drink Industry in Improving Child Health in Sub-Saharan Africa. Pediatrics. 2010;126(6):e1617-e21.

8. World Health Organization. Global health risks: mortality and burden of disease attributable to selected major risks: World Health Organization; 2009.

9. Monteiro CA, Conde WL, Popkin BM. The Burden of Disease From Undernutrition and Overnutrition in Countries Undergoing Rapid Nutrition Transition: A View From Brazil. American Journal of Public Health. 2004;94(3):433-4.

10. Popkin BM, Doak CM. The Obesity Epidemic Is a Worldwide Phenomenon. Nutrition Reviews. 1998;56(4):106-14.

11. Rendall MS, Weden M, Fernandes M, Vaynman I. H ispanic and black US children's paths to high adolescent obesity prevalence. Pediatric obesity. 2012;7(6):423-35.

12. Dary O, Hurrell R. Guidelines on food fortification with micronutrients. Geneva: World Health Organization, Food and Agricultural Organization of the United Nations. 2006.

13. Ritchie H, Roser M. Micronutrient deficiency. Our World in data. 2017. 
14. Darnton-Hill I. Chapter 2 - Prevalence, Causes, and Consequences of Micronutrient Deficiencies. The Gap Between Need and Action. In: Mannar MGV, Hurrell RF, editors. Food Fortification in a Globalized World: Academic Press; 2018. p. 13-28.

15. Bielecka-Jasiocha J, Majcher A, Pyrzak B, Janczarska D, Rumińska M. Overweight and obesity in preschool children: an underestimated problem? Przeglad Lekarski. 2009;66(1-2):45-8. 16. Ke-You G, Da-Wei F. The magnitude and trends of under-and over-nutrition in Asian countries. Biomedical and environmental sciences: BES. 2001;14(1-2):53-60.

17. KNBS, Macro ICF. Kenya Demographic and Health Survey 2014. 2015.

18. Olack B, Burke H, Cosmas L, Bamrah S, Dooling K, Feikin DR, et al. Nutritional status of under-five children living in an informal urban settlement in Nairobi, Kenya. J Health Popul Nutr. 2011;29(4):357-63.

19. Gorstein J. Assessment of nutritional status: effects of different methods to determine age on the classification of undernutrition. Bulletin of the World Health Organization. 1989;67(2):143. 20. Martin-moreno JM, Boyle P, Gorgojo L, Maisonneuve P, Fernandez-rodriguez JC, Salvini $\mathrm{S}$, et al. Development and validation of a food frequency questionnaire in Spain. International journal of epidemiology. 1993;22(3):512-9.

21. Coates RJ, Serdula MK, Byers T, Mokdad A, Jewell S, Leonard SB, et al. A brief, telephone-administered food frequency questionnaire can be useful for surveillance of dietary fat intakes. The Journal of nutrition. 1995;125(6):1473-83.

22. Health UDo, Services H. Code of Federal Regulations, Title 45, Part 46, Protection of Human Subjects. Revised 15 Jan 2009. 2014.

23. Chatfield C. Introduction to multivariate analysis: Routledge; 2018.

24. Metrine W, Omoro NO. MICRO-CREDIT AND POVERTY REDUCTION AMONG SELF HELP GROUPS WITHIN KISUMU COUNTY, KENYA. African Development Finance Journal (ADFJ). 2019;3(1).

25. Shamir R. The benefits of breast feeding. Protein in Neonatal and Infant Nutrition: Recent Updates. 86: Karger Publishers; 2016. p. 67-76.

26. Dinga L, Kiage B, Kyallo F. The participation of fathers in breastfeeding process: knowledge, beliefs, and practices in Kisumu, Kenya. African Journal of Food, Agriculture, Nutrition and Development. 2018;18(3):13634-45.

27. National Bureau of Statistics-Kenya II. KDHS. Rockville, Maryland, USA: KNBS and ICF International. 2014.

28. National Bureau of Statistics-Kenya II. 2014 KDHS key findings. Rockville, Maryland, USA: KNBS and ICF International. 2015.

29. World Health Organization. The optimal duration of exclusive breastfeeding: a systematic review. World Health Organization, 2001.

30. Doherty T, Sanders D, Jackson D, Swanevelder S, Lombard C, Zembe W, et al. Early cessation of breastfeeding amongst women in South Africa: an area needing urgent attention to improve child health. BMC pediatrics. 2012;12(1):105.

31. World Health Organization. Infant and young child feeding: model chapter for textbooks for medical students and allied health professionals: World Health Organization; 2009.

32. Geneva S. The optimal duration of exclusive breastfeeding. A systematic review Geneva WHO. 2001.

33. van der Meulen Rodgers Y, Kassens AL. Women's asset ownership and children's nutritional status: Evidence from Papua New Guinea. Social Science \& Medicine. 2018;204:1007. 
34. Udoh EE, Amodu OK. Complementary feeding practices among mothers and nutritional status of infants in Akpabuyo Area, Cross River State Nigeria. SpringerPlus. 2016;5(1):2073.

35. Hendriks A. Chubby Children: The Role of Social Norms on Parents Food Choices: [Netherlands]:[publisher not identified]; 2019.

36. Hoang NT, Orellana L, Le TD, Gibson RS, Worsley AF, Sinclair AJ, et al. Anthropometric status among 6-9-year-old school children in rural areas in Hai Phong City, Vietnam. Nutrients. 2018;10(10):1431.

37. Huus K, Ludvigsson JF, Enskär K, Ludvigsson J. Exclusive breastfeeding of Swedish children and its possible influence on the development of obesity: a prospective cohort study. BMC pediatrics. 2008;8(1):1-6.

38. Baker JL, Michaelsen KF, Rasmussen KM, Sørensen TI. Maternal prepregnant body mass index, duration of breastfeeding, and timing of complementary food introduction are associated with infant weight gain. The American journal of clinical nutrition. 2004;80(6):1579-88.

39. Bereket A, Atay Z. Current status of childhood obesity and its associated morbidities in Turkey. J Clin Res Pediatr Endocrinol. 2012;4(1):1-7.

40. Hawkes C, Popkin BM. Can the sustainable development goals reduce the burden of nutrition-related non-communicable diseases without truly addressing major food system reforms? BMC medicine. 2015;13(1):1-3.

41. Frison EA, Cherfas J, Hodgkin T. Agricultural biodiversity is essential for a sustainable improvement in food and nutrition security. Sustainability. 2011;3(1):238-53.

42. Trichopoulou A, Vasilopoulou E, Georga K, Soukara S, Dilis V. Traditional foods: Why and how to sustain them. Trends in Food Science \& Technology. 2006;17(9):498-504.

43. Ijarotimi O, Ashipa F. Evaluation of nutritional composition, sensory and physical property of home processed weaning food based on low cost locally available food materials. Nutrition \& Food Science. 2006. 
Figures

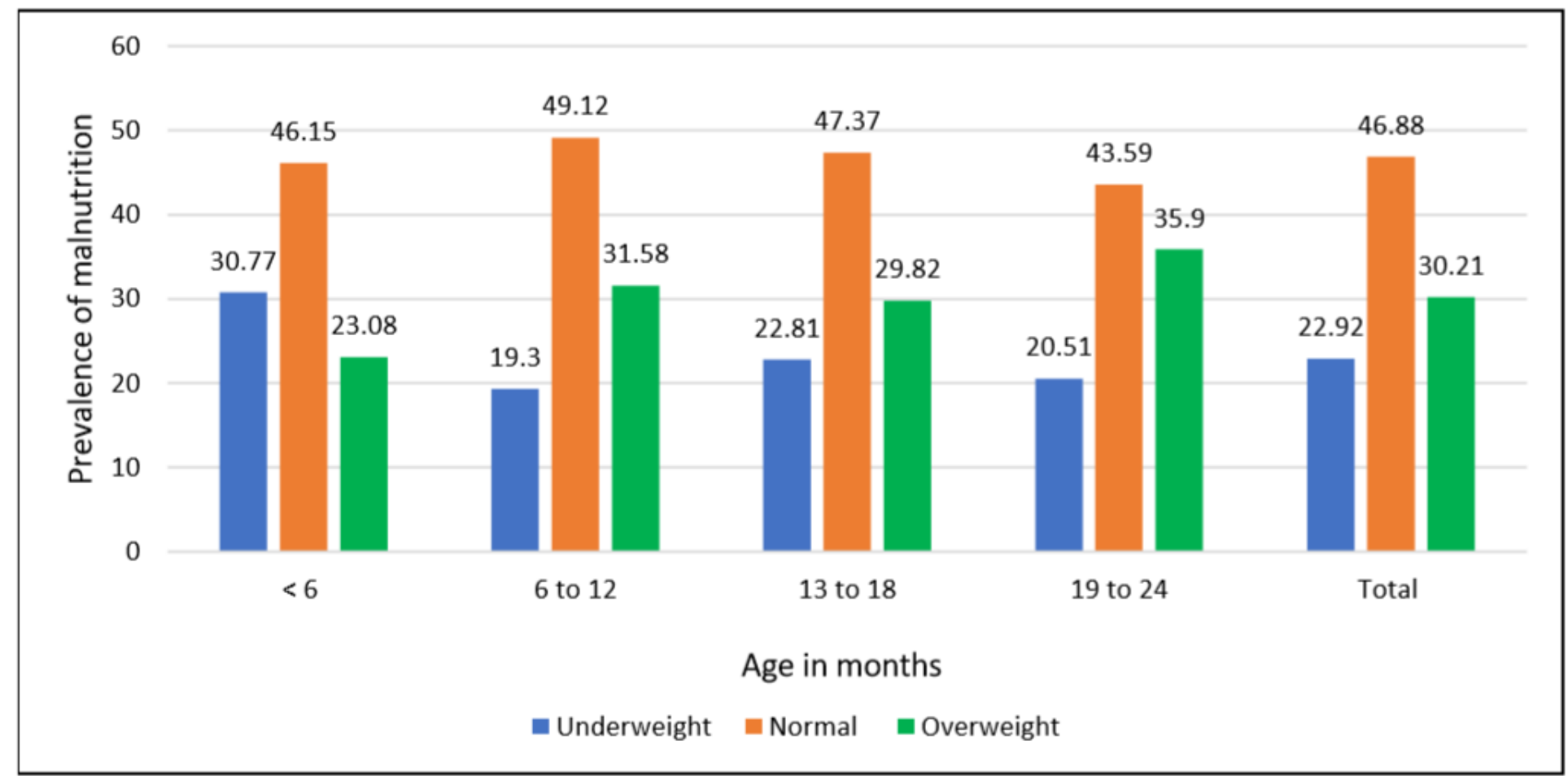

Figure 1

Prevalence of undernutrition and overnutrition among children in Kisumu County

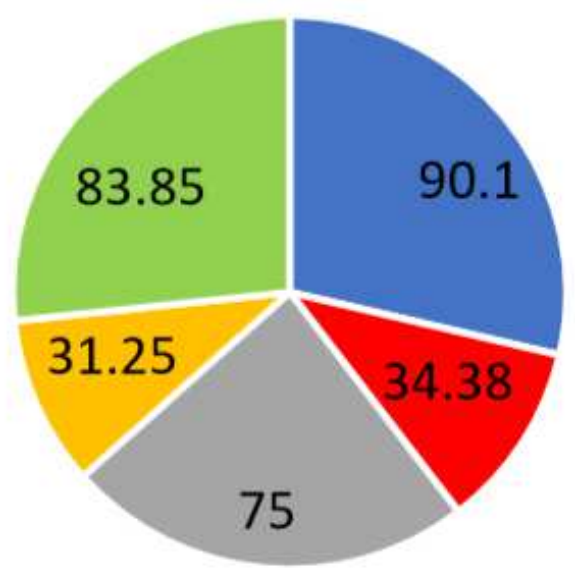

$\mathrm{CHO}=$ protein $\approx$ fat $=$ iron $\approx$ Vitamin $\mathrm{A}$

Figure 2

Adequacy of nutrient intake among children in Kisumu County 